\title{
English Speaking Skill and Indian Undergraduate ESL Learners: Interleaving or Block Practice?
}

\author{
Sujata Kakoti ${ }^{1}$, Sarat Kumar Doley ${ }^{2}$ \\ 1PhD Scholar, Dept of English, Tezpur University,sujata7980@gmail.com \\ ${ }^{2}$ Asst. Prof, Dept of English, Tezpur University, dolesar@tezu.ernet.in
}

\begin{abstract}
Recent studies showed that compared to practicing language skills in A stepwise manner over a period known as block practice, mixing the units of learning, and making them less predictable by presenting them randomly to the language learners, known as interleaving, may prove to be a more effective approach to language teaching (Finkbeiner\&Nicol, 2003; Schneider et al., 1998, 2002; Miles, 2014; Nakata, 2015). This paper is an attempt at reporting the findings of a 24-day long experimental study on the pedagogical effect of the interleaving and block practice approach to language learning (speaking skill in the present context) on undergraduate English as a second (ESL) learner. The teaching experimentation was done online on 36 undergraduate learner participants at the School of Sciences in Tezpur University during the Autumn Semester, 2020-21. The interleaving group showed slightly better language pedagogical results in speaking skills in English than the block practice group. It is, however, stated that the difference in performance was not found to be statistically significant. The performance of the two groups across the four micro-skills of speaking in English identified as interaction, pronunciation, fluency \& coherence, and vocabulary \& grammar remained static within the duration of the experimentation. Additionally, the groups did not demonstrate any significant difference in their L2 attitude and motivation over time.
\end{abstract}

Keywords: Interleaving; Block Practice; ESL; Speaking Skill; Attitude; Motivation; Language Pedagogy.

\section{Introduction}

English is the associate official language and the statutory working language of parliamentary law-making and the judiciary (Ind. Const. pt. XVII, art. 343,348) in India. It is the language of the intellect and formality and is considered a distinction of social class (Sailaja, 2009; NCEE, 2005). English language learning is a matter of importance in India both from the perspective of the economic progress of the individual and the perspective of the greater policy-making issues of the state (Annamalai, 2005). By 2002, 13 percent of primary schools, 18 percent of upper primary, and 26 percent of secondary schools in India purported to be English-medium (Meganathan, 2011). In an exciting drive to boost English language education, English is now taught from standard I in 26 states of the 35 states and union territories of the country, and most states allocate six 40-minute periods of instructional time per week to English in the country (Yadav, 2011). Amidst this enthusiasm, however, there is a parallel unease in the country about the actual increase in English language proficiency level among students. The principal objective of this paper

This Open Access article is published under a Creative Commons Attribution Non-Commercial 4.0 International License (http://creativecommons.org/licenses/by-nc/4.0/), which permits non-commercial re-use, distribution, and reproduction in any medium, provided the original work is properly cited. For citation use the DOI. For commercial re-use, please contact editor@rupkatha.com. 
is to report the findings of an experimental study on the effects of interleaving and block practice mode of teaching on two groups of undergraduate English as a second language (ESL) learner. The secondary objective is to measure the differences in $L 2$ attitude and motivation during the 24-day long teaching experimentation. The language pedagogical findings reported in this paper should help design a better ESL course for Indian undergraduate ESL learners. Considering the importance of learning English in India and the poor pedagogical infrastructure in most of the country, better language pedagogical methods should always be a matter of curiosity.

\section{Literature Review}

Often, learners are given exposure to a variety of skills in academic settings. In such a situation, they learn by practicing the skills over a while and move to the next, known as the block practice. However, recent studies show that learning is much more effective if the skills are mixed and less predictable. This practice is called interleaving. For instance, Rohrer and Taylor (2007) taught students to calculate the volume of 4 different types of solid figures. They were allowed to practice the problems either from simple to complex or interleaved by shuffling those. Later, when they were allowed to calculate the volumes for similar types of figures, they scored higher as they learned through interleaving. Kornell and Bjork (2008) taught participants to classify paintings of artists through blocked and interleaving methods. When the test was taken, it showed that the participants who practiced interleaving performed better. Similarly, Kang and Pashler (2012) used similar paintings, and interleaving has also been shown to benefit participants' abilities to distinguish the different species of birds (Wahlheim, Dunlosky, \& Jacoby, 2011). In this paper, an attempt has been made to show the differences in the performance of the spoken sub- skills between the groups.

A comparison has been made between the effects of interleaving and block practice on L2 vocabulary by three researchers. A translation task was conducted on the participants immediately after learning 32 pseudowords where there was a mixed and blocked condition. The participants' response speed was faster in the former condition than the latter, which concluded that the effect of interleaving was better for L2 vocabulary learning. (Finkbeiner\&Nicol, 2003; Schneider et al., $1998,2002)$. On the contrary, Schneider et al. $(1998,2002)$ could not show any advantage of interleaving over block practice.

Moreover, spaced learning often leads to superior retention compared to massed learning, including L2 grammar (Miles, 2014) and vocabulary (Nakata, 2015).There are more opportunities for practice that are distributed over multiple occasions. But, in massed learning, practice takes place continuously without any intervals (Rogers, 2017). Interleaving thus introduces spacing.

The effects of interleaving on L2 grammar learning were first examined by Pan and colleagues (2018). Their study is the first to demonstrate the benefits of interleaving for L2 grammar learning. Two grammar rules in Spanish (preterite and imperfect past tenses) were introduced to Englishspeaking college students under blocked or interleaved conditions. It is to be noted that the participants did not have any prior knowledge of the target language (Spanish) during the study. However, in the first two experiments, no significant difference was found between interleaving and block practice, but in the last two experiments, the post-test scores were higher in the 
interleaved practice. The present study also compares the effects of blocking and interleaving on the acquisition of spoken skills at the tertiary level.

Many researchers have shown that interleaving is useful for experienced learners while blocking for beginners (e.g., Guadagnoli, Holcomb, \& Weber, 1999; Rey, Wughalter, \& Whitehurst, 1982). Porter and Magill (2010) argued that it can be explained by the desirable difficulty framework (Bjork, 1999). If they are taught according to the appropriate level of difficulty, it facilitates longterm retention. Interleaving leads to more contextual interference than blocking. The interleaved practice may be too difficult for the beginners, which results in inefficient learning, but helps introduce the appropriate level of difficulty to experienced learners. Interleaved practice can be a "desirable difficulty" as it can cause stress in the initial performance of the learner but facilitates long-term retention and transfer performance (Bjork, 1994). A learner can learn faster in blocked practice, but it will not lead to long-term retention. (Soderstrom\& Bjork,2015). Interleaving benefits have been practiced for learning algebraic rules (Mayfield \& Chase, 2002) and geometric concepts (Taylor \& Rohrer, 2010). Blocking benefits have been observed for learning to identify degrees of varying line segments (Goldstone, 1996) and French pronunciation rules (Carpenter \& Mueller, 2013).

Blocking should be used in the early stages of learning as the proficiency level of the learner is low. With rigorous practice, the proficiency level increases, and thus interleaving becomes more beneficial at that stage. As a result, the contextual interference increases. This practice is called increasing practice. It paves the way for an appropriate level of difficulty throughout the treatment (Porter et al., 2007; Porter \& Magill, 2010), which facilitates long-term retention, according to the level of difficulty (Bjork, 1999).Blocking leads to better performance during training. Interleaving often results in better long-term retention as mentioned earlier (Kang \&Pashler, 2012; Rohrer \& Taylor, 2007; Taylor \& Rohrer, 2010). Therefore, this study attempts to examine whether interleaving will have a positive impact on learners' learning of English spoken skills. To check their progress and learning, an unannounced delayed post-test is taken. Carvalho and Goldstone (2014) showed that blocked practice resulted in improved performance when there were similarities within and between low similarity categories of the exemplars. While experimenting with high-similarity categories, the pattern was reversed. Here, all the exemplars share a high level of similarity with other exemplars in the same category, as well as exemplars in different categories (Zulkiply\& Burt, 2013).

In the above discussion, it is seen that researchers have examined the effects of interleaving and block practice and made a comparison between the two. However, studies were done on a small number of non-L2 studies that emphasized the effects of a combination of the two (Porter et al., 2007; Porter \& Magill, 2010; Wong, Whitehill, Ma, \& Masters, 2013). These studies show that rather than focusing on either of the two practices, it is efficacious to apply both methods. A combination of these two methods will facilitate different dimensions of learning and propose the benefits of both practices. While blocking may help identify the commonness within each category, interleaving may help make a clear distinction among different categories (Kang, 2016).

It is, therefore, very important to identify how learning can be affected by different conditions when the same information is presented to a varied group of learners. If learners are not capable 
enough to acquire the skills with the same input, it is to be taken into notice how improvements can be made with different practices (Atkinson, 1972; Pavlik and Anderson, 2008). L2 learners should be competent to articulate their speech and enhance their learning of L2. This study too examines whether either of the methods allows them to perform in a better way.

\section{Research Questions}

Keeping in view the principal objective of measuring the change in the spoken skill proficiency of the interleaving and the block practice groups and the difference in achievement, the study proposed the following three research questions-

1. Is the interleaving technique of teaching $L 2$ more effective in teaching the spoken microskills of interaction, pronunciation, fluency and coherence, and vocabulary and grammar than the block practice technique?

2. How does the spoken skill performance of the interleaving group differ from the spoken skill performance of the block practice group?

3. Does the $L 2$ attitude and motivation of the interleaving group remain more constant/ show more upward mean scores throughout the teaching experimentation than the attitude and motivation of the block practice group?

\section{Research Methods}

\section{Participants}

The experimentation was conducted at Tezpur University via online mode during the Spring semester of 2021. The initial plan of the experimentation was classroom sessions in face-to-face mode and the logistic arrangements at the Department of English of the university had been placed in the spring semester of 2020. The required permission from the concerned authority was also obtained for the experimentation. Unfortunately, the experimentation in the face-to-face mode could not be undertaken for the outbreak of COVID-19 and the lockdown from March 2020 following it. As the university did not allow a face-to-face mode of teaching since then, the online mode was the only medium to undertake the teaching experimentation.

The participants were selected from first-semester students enrolled in the undergraduate Sciences programmes in the university based on an online oral interaction through Google meet. The students needed to respond to the instructor's questions regarding their expectations from English language teaching classes by speaking for 6-10 minutes. Their oral responses were recorded for assessment of their speaking proficiency in English. The audio recordings of the students' responses to the instructor's questions were evaluated using the assessment criteria specified by the Central Board of Secondary Education (CBSE), India. The assessment criteria used by the CBSE for spoken skill tests focus on four major sub-skills: interaction, pronunciation, fluency \& coherence, and vocabulary \& grammar. The selection of students for the oral interaction was completely random and an attempt was made to look for students with lower spoken proficiency in English. After the assessment of the audio recordings, 35 students were recruited for the 
experimentation, and they were divided into two groups: control and interleaving. There were 3 assessors, and the audio recordings were assessed by them after a thorough discussion on the assessment criteria and the descriptors. The assessment was done separately by the assessors and the scores were compiled in an excel sheet. The mean score of the students was calculated and the students who obtained scores very close to the mean score were selected for the experimentation. As shown in Appendix 1, there were 15 and 20 learner participants in the control and the interleaving group respectively. 8 learner participants in the control group and 9 learner participants in the interleaving group were female. The participants in both groups were in the age group of 18-19.

\section{Teaching platform}

Although the initial plan of the experimentation had been designed for an offline and face-toface mode of interaction with the learner participants, it had to be changed to the online mode of teaching for the outbreak of COVID-19, the resultant lockdown, and closure of higher educational institutions in India indefinitely from March 2020. The online learning management system adopted for the experimentation was Google classroom. This was partly done because of the institutional preference for $\mathrm{G}$ Suite based Google classroom at the host institution, and partly for the personal preference of the instructor. A common Google classroom for the selection of the learner participants for the experimentation was created and around 44 students from the undergraduate Sciences programmes at Tezpur University were enrolled in the classroom. After the interaction, 2 new Google classrooms were created and the learner participants were further enrolled in these classrooms according to the division of the learner participants into 2 groups: control and interleaving. 15 students were enrolled in the control group classroom and there were 20 students in the interleaving group classrooms. These online learning management systembased classrooms were created mainly for group communication, uploading of teaching materials on the days of the revision, and classworks. The Google meet links for the live sessions were generated on a daily basis before the sessions and forwarded to the concerned group using a WhatsApp group created for immediate communication with the group. The Google meet links had to be generated each day for both groups because the option of recording the teaching sessions became non-functional after repeated use. The online sessions in the Google classrooms were conducted separately at different hours of the day and utmost care was taken to prevent information sharing between the two groups.

\section{Teaching material}

A needs analysis was done using the inputs provided by the students during the online interaction with the instructor to prepare language teaching objectives for the experimentation. It was noted that most of the students expressed the need of learning how to speak English in interviews related to job placement. Accordingly, four major areas of oral interaction, as shown in Table 2, in job placement interviews were identified for the teaching experimentation: introduction, hobby, native place, and strengths \& weaknesses. The selection of these areas was also based on the 
inputs received from the students during the oral interaction sessions. These major skill areas, as it is shown in Table 2, were further divided into 16 related micro skill areas such as introducing oneself, providing educational information, introducing the family, and brief personality information in the introduction category; speaking about a principal hobby, speaking about fitness concerns, speaking about reading habits, and speaking about spending time with relatives in the category of a hobby; describing the location, peoples' occupation, speaking about the climate of the place, and personal impression of the native place in the category of native place; and speaking about one's qualities in general, highlighting one principal quality, giving examples of other related qualities, and confessing a weakness in the category of strengths and weakness. The selection of the micro-skills areas was done by following the general trend observed in the structure of interviews related to job placement in private companies. No specific attempt at identifying the actual trends in the interview format followed in such interviews was done because the principal goal of writing the lessons was to provide scope for maximum English language practice. It is however stated that an accurate and more specific representation of the actual communication areas in job placement interviews may more meaningfully contribute to the learner participants' motivation towards the sessions.

There were 5 major components in the materials used for teaching the 16 micro skill areas identified for the teaching experimentation. As shown in Table 2, these components were YouTube videos, video clips of the English sentences, PPT slides showing the sentences separately, PPT slides with exercises, and video clips with background music displaying the exercise for revision. The YouTube videos were selected for initiation of the practice of the major spoken skill areas. The YouTube videos "Meeting someone for the first time", "Talking about hobbies and free time activities", "Talking about the native place", and "Know your character strengths" were downloaded and played in the first teaching sessions of introduction, hobby, native place, and strengths \& weaknesses respectively. These videos were used in the teaching sessions to prepare the learner participants for the English-speaking practices in the concerned speaking skill area.

In addition to the YouTube videos, four other teaching materials were prepared: video clips of the sentences in a paragraph with a voice-over, PPT slides displaying the sentences separately, PPT slides with fill in the gap/ scramble word exercises, and video clip with background music displaying the exercises for revision. In the video clips with the voice-over, all the sentences required to be learned in a particular session were shown together in a single video clip of approximately 1 minute 30 seconds on average. There were four to seven sentences in a single video clip and these sentences were read out in the form of a voice-over. The PPT slides with the sentences displayed each of the sentences on separate slides to assist the learner participants in focusing on the sentences closely. It also helps in memorizing the individual sentences related to a specific micro skill area. The objective of the PPT slides with the exercises is to provide an opportunity to the learner participants for the oral practice of the sentences before the roleplaying game. The exercise videos were played to the learner participants solely for the reinforcement of the language input provided to them in a particular session. The background music was added to the video to add an element of entertainment to the practice.

The video clips were prepared by the instructor with the help of video editing software and recording devices. The sentences were written on PPT slides, then converted to image files for use in the video editing software. The instructor recorded the audio of the sentences using a recorder 
device and the audio file was added to the video of the sentences with the help of the same video editing software. There were 16 such video clips in total corresponding to the 16 micro skill areas. The video clips used in the revision sessions needed to be collected in a single file so that all the sentences practiced in the previous 4 sessions could be revised in one go. The exercise video clips were also prepared using the same video editing software and the procedure. The PPT slides were prepared in the Microsoft PowerPoint Presentation facility in the Windows 10 version. 16 PPT slides were used to display the sentences separately for the 16 micro skill areas identified for the teaching sessions. In the revision sessions, the PPT slides of the 4 previous sessions were merged and shown to the learner participants for revision. The PPT slides containing the exercises were also prepared by the instructor and presented to the learner participants in a similar manner.

The preparation of the teaching materials was predominantly guided by the online mode of teaching. Since the interaction with the students was done through Google meet using a G-suite account, the medium offered both presentations and recording options for the sessions. The instructor moderated the sessions by displaying the PPTs and video clips to the learner participants. The teaching materials required no specific explanations by the instructor except for a couple of questions about some unfamiliar words. The audio-visual materials used in the teaching sessions were meant to represent examples of oral communication during job placement interviews. It was thought that the audio-visual method of teaching how to speak in English in a job placement interview was the best option available under the circumstances.

\section{Learner activities}

The learner participants were asked to watch, as shown in Table 1, the YouTube videos during the sessions on introducing oneself (A1), speaking about the principal hobby (B1), describing the location (C1), and speaking about one's quality in general (D1). The objective of making the learner participants watch the YouTube videos was to provide them with an orientation towards a new micro skill area. The learner participants were required to identify the themes of the videos and get themselves mentally ready for the oral practices around the concerned theme. The instructor played the video clips of the sentences in the concerned micro skill area once it was understood that the learner participants had figured out the theme correctly. The learner participants were asked to watch the video clips three times at a stretch. They were required to attentively listen to the voice-over reading out the sentences. The third activity for the learner participants was to read the sentences separately from the PPT slides displayed on the screen by the instructor. As the PPT slides were shown to the learner participants, the instructor requested them to concentrate on the sentences and to listen attentively to the instructor's reading of the sentences. This activity provided an opportunity to the learner participants to revise the sentences several times and prepare them for the exercises.

The exercises, as shown in Table 1, were of 2 types: fill-in-the-gap and scrambled sentences. Fillin-the-gap exercises were assigned to the learner participants in 13 lessons, whereas there were 3 scrambled sentences exercises. The choice of the oral exercise was dependent on the nature of the sentences for practice. If the sentences contained lots of personal information, then fill in the gap exercises were chosen. These exercises provided the learner participants an opportunity to 
practice the sentences by incorporating their personal information. Some sentences for practice did not contain personal information, as the contents were general and suitable for all. Since the fill-in-the-gap exercises could not be performed in such cases, the scrambled sentence exercise had to be used. The learner participants were required to note down the sentences in the exercise and write their answers. They were given 3-5 minutes to write the answers and the instructor randomly decided on the order of response by the learner participants. All the learner participants were required to read out their answers to the class and the instructor provided feedback to their answers individually as and when it was required. This activity prepared the learner participants for the most important oral practice activity in the sessions: role-playing. The instructor acted as the interviewer of a job placement interview and the learner participants had to play the role of interviewees. The learner participants were asked a question by the instructor as the interviewer that would invite the sentences practiced in the session as the responses from them. The order of the interview appearance was randomly decided by the instructor and the order was changed in every session.

Normally, the learner participants had to respond to the interview question without using the notebook, but in circumstances where a particular learner participant found it difficult to respond extempore, the use of the notebook was allowed. The last activity in the sessions was the revision of the sentences using the exercise videos with background music. As the instructor played the video, the learner participants needed to say the complete sentences out loud together. This activity was repeated three times and it was ensured by the instructor that all the learner participants participated in the revision activity. It generally concluded all the sessions except for the four revision sessions in which, as shown in Table 1, an additional task of a home assignment was given to the learner participants. The home assignments were based on the 4 sessions before the concerned revision session in which the learner participants needed to speak in response to a question, record the speech, and upload it in the classwork page of the Google classroom used for the sessions. 
9 English Speaking Skill and Indian Undergraduate ESL Learners: Interleaving or Block

Practice?

Table 1. Activities and teaching materials related to the specified spoken skill areas (BP = Block Practice; IL=Interleaving)

\begin{tabular}{|c|c|c|c|}
\hline $\begin{array}{c}\text { Spoken skill } \\
\text { areas (Skill } \\
\text { code) }\end{array}$ & Sub- skills (Lesson code) & Learner activities & Teaching materials \\
\hline $\begin{array}{l}\text { Native place } \\
\text { (C) } \\
\text { Strengths \& } \\
\text { weakness (D) }\end{array}$ & $\begin{array}{l}\text { Introducing oneself (A1) } \\
\text { Providing educational information (A2) } \\
\text { Introducing the family (A3) } \\
\text { Brief personality information (A4) } \\
\text { Speaking about a principal hobby (B1) } \\
\text { Speaking about fitness concerns (B2) } \\
\text { Speaking about reading habits (B3) } \\
\text { Speaking about time with relatives (B4) } \\
\text { Describing the location (C1) } \\
\text { People's occupation (C2) } \\
\text { Speaking about the climate of the place (C3) } \\
\text { One's impression of the native place (C4) } \\
\text { Speaking about one's qualities in general (D1) } \\
\text { Highlighting one principal quality (D2) } \\
\text { Giving examples of other related qualities (D3) } \\
\text {---Confessing a weakness (D4) }\end{array}$ & $\begin{array}{l}\text { 1. Watching the YouTube video } \\
\text { (lesson } 1,6,11 \text {, and } 16 \text { for BP and } \\
\text { lesson } 1-4 \text { for IL). } \\
\text { 2. Revision of the previous session. } \\
\text { (Excluding lessons } 1,6,11 \text {, and 16). } \\
\text { 3. Watching the video clips related to } \\
\text { the sub-skills. } \\
\text { 4. Reading the individual sentences } \\
\text { from the PPT slides. } \\
\text { 5.Fill-in-the-gap exercises (lesson 1-4, } \\
6,11-14,16-19 \text { for BP and lesson } 1-4 \text {, } \\
6,9,11-14,17-19 \text { for IL) / scrambled } \\
\text { sentences exercises (lesson } 7-9 \text { for BP } \\
\text { and lesson } 7,8 \text { and } 16 \text { for IL). } \\
\text { 6. Reading the answers. } \\
\text { 7. Role Playing. } \\
\text { 8. Revision of the sentences using the } \\
\text { fill-in-the-gap/scrambled sentences } \\
\text { exercises. } \\
\text { 9. Home assignment after the } \\
\text { revision sessions. }\end{array}$ & $\begin{array}{l}\text { 1. YouTube videos on "Meeting someone } \\
\text { for the first time." (Lesson } 1 \text { both for BP and } \\
\text { IL), "Talking about hobbies and free time } \\
\text { activities" (lesson } 6 \text { for BP and lesson } 3 \text { for } \\
\text { IL), "Talking about the native place" (lesson } \\
11 \text { for BP and lesson } 2 \text { for IL) and "Know } \\
\text { your character strengths" (lesson } 16 \text { for BP } \\
\text { and lesson } 4 \text { for IL). } \\
\text { 2. Video clips of the related sub-skills. } \\
\text { 3. PPT slides containing the individual } \\
\text { sentences in the video clips. } \\
\text { 4.PPT slides with Fill in the gap (lesson 1-4, } \\
6,11-14,16-19 \text { for BP and lesson } 1-4, \\
6,9,11-14,17-19 \text { for IL) / scrambled } \\
\text { sentences (lesson } 7-9 \text { for BP and lesson } 7,8 \\
\text { and } 16 \text { for IL)exercises. } \\
\text { 5. Exercise video clips exercise containing } \\
\text { background music for revision. }\end{array}$ \\
\hline
\end{tabular}




\section{Sequence of the micro skill areas}

There were 4 major spoken skill areas and 16 micro spoken skill areas corresponding to them, as described in the section on teaching material in this paper, and the sequence of the lessons on the micro-skills was different for the two groups. As shown in Table 2, the 24-day session plan for the control group was arranged according to the traditional block practice approach. Following this

Table 2. Sequence of the micro-skills (Home Assignment=HA; Revision=R)

\begin{tabular}{|c|c|c|c|}
\hline Day & BP Lesson sequence & IL Lesson sequence & ${ }^{\mathrm{a}}$ Duration of the sessions \\
\hline 1 & $\mathrm{~A} 1$ & $\mathrm{~A} 1$ & 1 hour (approx.) \\
\hline 2 & $\mathrm{~A} 2$ & $\mathrm{C} 1$ & 1 hour (approx.) \\
\hline 3 & $\mathrm{~A} 3$ & B1 & 1 hour (approx.) \\
\hline 4 & A4 & D1 & 1 hour (approx.) \\
\hline 5 & BPR1 $(A 1, A 2, A 3, A 4)$ & ILR1 (A1,C1,B1,D1) & 1 hour 30 mins (approx.) \\
\hline 6 & BP HA1 & IL HA1 & Within 24 hours \\
\hline 7 & B1 & $\mathrm{A} 2$ & 1 hour (approx.) \\
\hline 8 & B2 & B2 & 1 hour (approx.) \\
\hline 9 & B3 & B3 & 1 hour (approx.) \\
\hline 10 & B4 & D2 & 1 hour (approx.) \\
\hline 11 & BPR2 (B1,B2,B3,B4) & ILR2 (A2,B2,B3,D2) & 1 hour 30 mins (approx.) \\
\hline 12 & BP HA2 & IL HA2 & Within 24 hours \\
\hline 13 & $\mathrm{C} 1$ & $\mathrm{~A} 3$ & 1 hour (approx.) \\
\hline 14 & $\mathrm{C} 2$ & A4 & 1 hour (approx.) \\
\hline 15 & C3 & $\mathrm{C} 2$ & 1 hour (approx.) \\
\hline 16 & $\mathrm{C} 4$ & C3 & 1 hour (approx.) \\
\hline 17 & BPR3 $(\mathrm{C} 1, \mathrm{C} 2, \mathrm{C} 3, \mathrm{C} 4)$ & ILR3 $(A 3, A 4, C 2, C 3)$ & 1 hour 30 mins (approx.) \\
\hline 18 & BP HA3 & IL HA3 & Within 24 hours \\
\hline 19 & D1 & B4 & 1 hour (approx.) \\
\hline
\end{tabular}



20
D2
D3
1 hour (approx.)
21
D3
C4
1 hour (approx.)
22
D4
D4
1 hour (approx.)
ILR4 (B4,D3,C4,D4)
1 hour 30 mins (approx.)
Within 24 hours

aFor each group

approach, the related micro skills within a specific major spoken skill area were placed together in sequence in which the micro-skills were arranged according to the level of difficulty beginning with the relatively easier to follow micro skill (Thorndike). For instance, the A1 lesson within the "Introduction" spoken skill area (A) was followed by A2, A3 and A4 consecutively. But in the interleaving group, the sequence of the lessons was arranged differently. As shown in Table 3, the regular order of lessons is broken, and the lessons are arranged randomly. Interleaving offers multiple ways of arranging lessons and the way of arrangement followed for the experimentation was acbd, abbd, aacc, bdcd. To keep the introductory lessons in the first 4 days of the experimentation, the A1 lesson of major spoken skill area A, C1 lesson of major spoken skill area C, B1 of major spoken skill area B, and D1 of major spoken skill area D were presented to the learner participants. After this arrangement for the first 4 sessions, the rest of the 12 sessions were arranged randomly following the interleaving sequence of $a b b d$, aacc, bdcd. The principal reason for keeping the first 4 lessons in the first 4 sessions of the teaching experimentation was to minimize the randomness of the arrangement so that the learner participants can relate the rest of the forthcoming 12 sessions with the introductory 4 sessions. In addition to the 16 sessions on the specified micro skill areas, there were 4 revision sessions of 1 hour and 30 minutes each approximately. The revision sessions, as shown in Table 2, constituted of the 4 consecutive sessions held in the previous 4 days of the teaching experimentation. The revision sessions were used as sessions of reinforcement of the learning received in the earlier 4 sessions and they were held on the fifth day followed by a break of a day for home assignments on the sixth.

\section{Results and Discussions}

\section{Effectiveness of block practice and interleaving in the teaching of L2 spoken skill}

To measure the effectiveness of the teaching practices used in the experimentation the following research question was asked-

Research Question No.1: Is the interleaving technique of teaching L2 more effective in teaching the spoken micro-skills of interaction, pronunciation, fluency \& coherence, and vocabulary $\&$ grammar than the block practice technique? 
12 | Rupkatha Journal, Vol. 13, No. 4, 2021

Table 3. Pre instruction test scores of spoken skills in English (Online interaction $=O I ; B P=B l o c k$ practice; IL = Interleaving)

\begin{tabular}{lcccccc}
\hline Sub skills & Test mode & Group & $M($ and $S D)$ & $d f$ & $F$ & Sig. \\
\hline Interaction & OI & BP & $11.23(1.42)$ & 1,28 & 28.88 & .000 \\
& IL & $7.88(1.87)$ & & & \\
Pronunciation & OI & BP & $11.54(1.61)$ & 1,28 & 51.84 & .000 \\
$\begin{array}{l}\text { Fluency \& } \\
\text { Coherence }\end{array}$ & OI & IL & $7.18(1.67)$ & & & .000 \\
$\begin{array}{l}\text { Vocabulary \& } \\
\text { Grammar }\end{array}$ & OI & IL & $11.46(1.33)$ & 1,28 & 68.29 & \\
& & BP & $10.23(2.05)$ & 1,28 & 34.24 & .000 \\
$\begin{array}{l}\text { Speaking skill } \\
\text { (as a whole) }\end{array}$ & OI & IL & $6.53(1.42)$ & & & \\
& & BP & $44.46(5.35)$ & 1,28 & 55.73 & .000 \\
\hline
\end{tabular}

The spoken proficiency performance of the two groups in the online pre-test, as shown in Table 3 , differed in the 4 spoken sub-skill areas of interaction, pronunciation, fluency and coherence, and vocabulary and grammar. The mean scores of the BP group in interaction, pronunciation, fluency and coherence, and vocabulary and grammar spoken sub-skills during the pretest were $11.23,11.54,11.46$, and 10.23 respectively. These mean scores displayed homogeneity along the 4 spoken sub-skills as the $S D$ was between 1.33 and 2.05 . The mean scores were also within the range of 10.23 and 11.54 for all the 4 speaking sub-skills. The mean scores of the IL group in interaction, pronunciation, fluency \& coherence, and vocabulary \& grammar sub-skills in the pretest were $7.88,7.18,7.12$, and 6.53 respectively. The IL group also showed homogeneity as the mean scores and $S D$ were within the range of 6.53 and 7.88 , and 1.42 and 1.87 respectively. Although the mean score ranges of the two groups differed, as the block practice group showed higher mean scores, the within-group speaking sub-skill mean scores were homogeneous. Since one of the main objectives of the experimentation was to test the effectiveness of the two teaching methods- BP and IL- the differences in the mean scores, even though statistically significant, should not intervene in the measurement of the mean scores of the post-test for the existence of homogeneity in the mean scores of the two groups in the pre-test.

Moreover, as shown in Table 4, the spoken proficiency performance of the two groups again differed in the 4 spoken sub-skill areas of interaction, pronunciation, fluency and coherence, and vocabulary and grammar. The scores contradicted the scores of the pre-test. During the post-test, the mean scores of the BP group in interaction, pronunciation, fluency $\&$ coherence, and 
vocabulary \& grammar sub-skills were $11.46,10.77,10.54$, and 10.54 respectively. These mean scores displayed homogeneity along the 4 spoken sub-skills as the $S D$ was between 2.50 and 3.15. The mean scores were also within the range of 10.54 and 11.46 for all the 4 spoken sub-skills. On the other hand, in the post-test, the mean scores of the IL group in interaction, pronunciation, fluency \& coherence, and vocabulary \& grammar sub-skills were 9.18, 7.53, 8.06, and 6.76 respectively. The IL group also showed homogeneity as the mean scores and $S D$ were within the range of 6.76 and 9.18 , and 1.75 and 2.35 respectively. From the discussion, it is seen that the mean scores differed between the groups. As found in the pre-test, the block practice group in the post-test too showed higher mean scores. The within-group speaking sub-skill mean scores were homogeneous. Here, the mean scores are statistically significant.

Table 4.Post instruction test scores of spoken skills in English (Online interaction=OI; $B P=B l o c k$ practice; IL = Interleaving)

\begin{tabular}{|c|c|c|c|c|c|c|}
\hline Sub skills & Test mode & Group & $M($ and $S D)$ & $d f$ & $F$ & Sig. \\
\hline \multirow[t]{2}{*}{ Interaction } & OI & $\mathrm{BP}$ & $11.46(2.90)$ & 1,28 & 5.67 & .024 \\
\hline & & IL & $9.18(2.35)$ & & & \\
\hline \multirow[t]{2}{*}{ Pronunciation } & OI & $\mathrm{BP}$ & $10.77(3.11)$ & 1,28 & 11.61 & .002 \\
\hline & & IL & $7.53(2.10)$ & & & \\
\hline \multirow{2}{*}{$\begin{array}{l}\text { Fluency \& } \\
\text { Coherence }\end{array}$} & OI & $\mathrm{BP}$ & $10.54(2.50)$ & 1,28 & 8.02 & .008 \\
\hline & & IL & $8.06(2.28)$ & & & \\
\hline \multirow{2}{*}{$\begin{array}{l}\text { Vocabulary \& } \\
\text { Grammar }\end{array}$} & OI & $\mathrm{BP}$ & $10.54(3.15)$ & 1,28 & 17.46 & .000 \\
\hline & & IL & $6.76(1.75)$ & & & \\
\hline
\end{tabular}

\section{Differences in spoken sub- skills performance between the groups}

To measure the differences between the subskill performances between the two groups the following research question was asked-

Research Question No.2: How does the speaking skill performance of the interleaving group differ from the spoken skill performance of the block practice group?

A comparison was made between the pre-test and post-test of the BP and IL group to check the spoken proficiency performance in different periods. As shown in Table 5, the learner participants showed significant differences across the 4 speaking sub-skill areas of interaction, pronunciation, fluency and coherence, and vocabulary and grammar in both tests. It was quite surprising that the mean values of the BP group were comparatively higher in the pre-test and the post-test than in the IL group. The mean values of the BP group were higher in the post-test in the spoken sub- 
skill area of interaction and, vocabulary and grammar which were 11.46 and 10.54 respectively. But in the pre-test, the mean values in the spoken sub-skill area of pronunciation and, fluency and coherence were 11.54 and 11.56 respectively that showed higher mean values. There was a slight variance in the $S D$ in the BP group since it ranged between 10.23 and 11.54 in the pre-test and between 10.54 and 11.46 in the post-test.

Unlike the BP group, the mean values of the IL group across the 4 spoken sub-skill areas of interaction, pronunciation, fluency \& coherence, and vocabulary \& grammar in the post-test were higher than the pre-test. There was an increase in the proficiency level in the sub-skill area of interaction and, fluency and coherence in the mean scores which were 9.18 and 8.06 respectively compared to the pronunciation and, fluency and coherence sub-skill area. A subtle difference can be seen in the $S D$ which was between 1.42 and 1.87 in the pre-test and 1.75 and 2.35 in the posttest.

Table 5. Comparison between Pre- instruction and Post- instruction test scores (Online interaction=OI; BP= Block practice; IL = Interleaving)

\begin{tabular}{lcccccccc}
\hline Sub skills & $\begin{array}{l}\text { Test } \\
\text { mode }\end{array}$ & Group & $\begin{array}{c}\text { Pre-in } M(\text { and } \\
\text { SD) }\end{array}$ & $\begin{array}{c}\text { Post- in } M(\text { and } \\
S D)\end{array}$ & $d f$ & $F$ & $\begin{array}{c}\text { Sig. } \\
\text { Effect } \\
\text { size }^{\text {a }}\end{array}$ \\
\hline Interaction & OI & BP & $11.23(1.42)$ & $11.46(2.90)$ & 1,28 & .066 & .802 & .005 \\
& & IL & $7.88(1.87)$ & $9.18(2.35)$ & 1,28 & 7.652 & .014 & .324 \\
$\begin{array}{l}\text { Pronunciati } \\
\text { on }\end{array}$ & OI & BP & $11.54(1.61)$ & $10.77(3.11)$ & 1,28 & .719 & .413 & .057 \\
$\begin{array}{l}\text { Fluency \& } \\
\text { Coherence }\end{array}$ & OI & BP & $11.46(1.33)$ & $10.54(2.50)$ & 1,28 & 1.267 & .282 & .095 \\
$\begin{array}{l}\text { Vocabulary } \\
\&\end{array}$ & OI & BP & $10.23(2.05)$ & $10.54(3.15)$ & 1,28 & .115 & .741 & .009 \\
Grammar & & IL & $6.53(1.42)$ & $6.76(1.75)$ & 1,28 & 1.000 & .332 & .059 \\
\hline
\end{tabular}

aartial Eta

It was quite evident that the BP group performed well in both tests. But it is to be noted that the effect sizes in the BP group were low which was between 0.005 and 0.095 across the sub-skills; however, it contrasted in the IL group between 0.046 and 0.327 which showed a higher effect size. The $F$ value of the BP and IL group in the sub-skill area of interaction and, fluency and coherence showed a high difference between 0.066 and 7.652 and 1.267 and 7.787 respectively. While the $F$ value was significantly different in pronunciation and, vocabulary and grammar sub-skill area of the BP and IL group was between 0.719 and 0.772 and, 0.115 and 1.000 respectively. From the discussion, it is seen that the performance of the learner participants was better after the intervention. Not much difference could be found among the learner participants of the BP group. The IL group, on the contrary, showed progress after the pre-test. 


\section{Differences in $\mathbf{L} 2$ attitude and motivation between the groups}

To measure the differences in L2 attitude and motivation between the two groups over time, the following research question was asked-

Research Question No.3: Does the $\mathrm{L} 2$ attitude and motivation of the interleaving group remain more constant/ show more upward mean scores throughout the teaching experimentation than the attitude and motivation of the block practice group?

To explore the different dimensions of the change in attitude and motivation of the learner participants during the treatment, the SA criteria comprising Need significance, Pleasantness, Novelty, Coping Potential, and Self/ social image was used for the study (See Appendix 2). The differences in attitude and motivation were assessed between the BP and IL group across the five stimulus appraisal criteria. As shown in Table 6, the values were obtained from the responses of the feedback forms provided every day at the end of the sessions to both the groups using the two-way ANOVA repeated measures.

The learner participants of the BP and IL group exhibited noticeable changes in all the SA criteria in different periods. The difference could be observed in the BP group where most of the mean values were higher than the IL group. The responses of the L2 learners towards the sessions in different weeks were the result that assessed the SA criteria of the learner participants and demonstrated their attitude towards the spoken skills. The mean values across the SA criteria created attitudinal differences among the participants. The items in the feedback form were divided according to the five SA criteria, which provided an opportunity to measure their attitude and motivation during the experimentation.

It could be seen from table 6 that the values of the SA criteria varied in different periods. Among all the five criteria, the mean values of $\mathrm{Pn}$ were higher in both groups in all 4 weeks. It was 4.93 in

Table 6. Change in attitude and motivation during the treatment (SA= Stimulus appraisal; NS= Need significance; $P n=$ Pleasantness; $N y=$ Novelty; $C P=$ Coping potential; SSI=Self $/$ social image; $B P=$ Block practice; $I L=$ Interleaving)

\begin{tabular}{ccccccccc}
\hline $\begin{array}{c}\text { SA } \\
\text { criteria }\end{array}$ & Group & $\begin{array}{c}\text { Week 1 } \\
\text { (and SD) }\end{array}$ & $\begin{array}{c}\text { Week 2 } \\
M \text { (and SD) }\end{array}$ & $\begin{array}{c}\text { Week 3 } \\
M \text { (and SD) }\end{array}$ & $\begin{array}{c}\text { Week 4 } \\
M \text { (and SD) }\end{array}$ & $F$ & $\begin{array}{c}\text { Sig. } \\
\text { Effect } \\
\text { size }\end{array}$ \\
\hline NS & BP & $4.86(.321)$ & $4.80(.369)$ & $4.98(.067)$ & $4.89(.401)$ & 2.166 & .150 & .371 \\
& IL & $4.69(.551)$ & $4.85(.415)$ & $4.60(.711)$ & $4.73(.473)$ & .350 & .790 & .095 \\
Pn & BP & $4.93(.268)$ & $4.98(.067)$ & $5.00(.000)$ & $4.80(.666)$ & 1.086 & .396 & .228 \\
& IL & $4.77(.314)$ & $4.81(.491)$ & $4.92(.188)$ & $4.85(.315)$ & .932 & .461 & .219 \\
Ny & BP & $4.79(.292)$ & $4.79(.308)$ & $4.89(.189)$ & $4.79(.545)$ & .613 & .621 & .143
\end{tabular}


16 | Rupkatha Journal, Vol. 13, No. 4, 2021

\begin{tabular}{rcccccccc} 
& IL & $4.73(.259)$ & $4.75(.559)$ & $4.75(.500)$ & $4.81(.370)$ & .145 & .931 & .042 \\
CP & BP & $4.82(.372)$ & $4.68(.532)$ & $4.86(.413)$ & $4.64(.633)$ & .549 & .659 & .130 \\
& IL & $4.17(.766)$ & $4.37(.781)$ & $4.46(.548)$ & $4.52(.681)$ & .593 & .634 & .151 \\
SSI & BP & $4.77(.576)$ & $4.82(.372)$ & $4.68(.541)$ & $4.77(.799)$ & .148 & .929 & .039 \\
& IL & $4.60(.582)$ & $4.58(.862)$ & $4.62(.888)$ & $4.62(.888)$ & .005 & .995 & .001 \\
\hline
\end{tabular}

apartial Eta ${ }^{2}$

week 1, 4.98 in week 2, 5.00 in week 3 and, 4.80 in week 4 in the case of the learner participants of the BP group. Whereas the mean values of the IL group for Pn of the SA criteria were 4.77, 4.81, 4.92 , and 4.85 in week 1, week 2, week 3 and, week 4 respectively. So, the differences in motivation scores were highly significant. It confirmed that the stimulus appraisal, $\mathrm{Pn}$ contributed to remarkably higher motivation towards L2 spoken proficiency.

But their attitude and motivation towards L2 spoken proficiency declined in CP of the IL group and, CP and SSI of the BP group. That displayed the lower motivational score where the mean values for the IL group of CP were 4.17 in week 1, 4.37 in week 2, 4.46 in week 3, and 4.52 in week 4. Furthermore, the learner participants of the BP group pointed towards the lower motivational mean values in week 2 and week 4 of the stimulus appraisal, CP where the values were 4.68 and 4.64 respectively. The same was in SSI in which the mean values in week 1 were 4.77 and, 4.68 in week 3.

The shift in the attitudinal changes and more consequential L2 spoken proficiency motivational difference could be determined from the mean values of the 4 weeks. It was quite surprising that the attitude and motivation level was consistent in the BP group in week 1, week 2 and, week 3 of the SA criteria, NS, Pn, and Ny where all the mean values displayed a significant upward slope. However, the motivation declined towards the $4^{\text {th }}$ week. Moreover, the mean values of CP and SSI criteria fluctuated in all the weeks. There was a sudden increase and decline in their attitude towards the sessions. Whereas the mean values of the IL group gradually increased from week 1 to week 4 in the SA criteria Ny, CP, and SSI. But the values decreased on week 4 of NS andPn.

The effect sizes were higher in the BP group between 0.039 and 0.371 in NS and SSI respectively unlike the IL group with lower effect sizes between 0.001 in SSI and 0.219 in Pn. The $F$ value of the BP and IL group in NS showed a high difference between 2.166 and 0.350 respectively- and, whereas in Ny it was 0.613 for the BP group and 0.145 for IL.

\section{Conclusions}

The 24-day experimentation showed several differences in effect between the interleaving and the control groups. First, the learner participants in the interleaving group performed slightly better in the post-test than what they performed in the pre-test compared to the learner participants in the control group across the four assessment criteria of interaction, pronunciation, fluency and coherence, and vocabulary and grammar. But the difference was not statistically 
significant. Second, the spoken skill performance of the interleaving group was better in the interaction, and fluency and coherence micro-skills than in the other two. The performance of the control in the post-test in comparison with their performance in the pre-test was not substantially different. Third, the ESL attitude and motivation factors did not show any difference between the two groups. In conclusion, it may be stated that an experimentation longer in duration should provide a more elaborate and specific understanding of the effect of the two approaches to teaching an $\mathrm{L} 2$.

\section{Acknowledgements}

The authors are indebted to the Department of Science and Technology (DST), Ministry of Science and Technology, Government of India, for the financial support to undertake the study. Gratitude is also expressed to Tezpur University for the logistic help during the study.

\section{References}

Annamalai, E. (2005). Nation-building in a globalised world: Language choice and education in India. In A.M.Y. Lin \& P. Martin (Eds.), Decolonization, globalization: Language-in-education policy and practice (pp. 20-37). Clevedon, UK: Multilingual Matters.

Atkinson, R.C.(1972).Optimizing The Learning Of A Second-language vocabulary. Journal of Experimental Psychology, 96, 124-129. https://doi.org/10.1037/h0033475

Bjork, R. A. (1994). Memory and metamemory considerations in the training of human beings. In Metacognition: Knowing about knowing (pp. 185-205). The MIT Press.

Bjork, R. A. (1999). Assessing our own competence: Heuristics and illusions. In D. Gopher \& A. Koriat (Eds.), Attention and performance XVII: Cognitive regulation of performance: Interaction of theory and application (pp. 435-459). Cambridge, MA: MIT Press.

Carpenter, S. K., \& Mueller, F. E. (2013). The effects of interleaving versus blocking on foreign language pronunciation learning. Memory \& Cognition, 41, 671- 682.https://doi.org/10.3758/s13421-0120291-4

Carvalho, P. F., \& Goldstone, R. L. (2014). Putting category learning in order: category structure and temporal arrangement affect the benefit of interleaved over blocked study. Memory \& Cognition, 42(3), 481-495.doi: 10.3758/s13421-013-0371-0

Finkbeiner, M., \&Nicol, J. (2003). Semantic category effects in second language word learning. Applied Psycholinguistics, 24, 369-383. https://doi.org/10.1017/S0142716403000195

Goldstone, R. L. (1996). Isolated and interrelated concepts. Memory \& Cognition, 24,608628.https://doi.org/ 10.3758/bf03201087

Guadagnoli, M. A., Holcomb, W. R., \& Weber, T. J. (1999). The relationship between contextual interference effects and performer expertise on the learning of a putting task. Journal of Human Movement Studies, 37, 19-3. 
Ind. Const. pt. XVII, art. 343.

Ind. Const. pt. XVII, art. 348.

Kornell, N., \& Bjork, R. A. (2008). Learning concepts and categories: Is spacing the "enemy of induction?".Psychological Science, 19, 585-592.https://doi.org/10.1111/j.1467-9280.2008. 02127.x

Kang, S. H. K., \&Pashler, H. (2012). Learning painting styles: Spacing is advantageous when it promotes discriminative contrast. Applied Cognitive Psychology, 26, 97-103. https://doi.org/10.1002/acp.1801

Kang, S. H. (2016). The benefits of interleaved practice for learning. In J. C. Horvath, J. M. Lodge, \& J. Hattie (Eds.), From the laboratory to the classroom: Translating science of learning for teachers (pp. 7993). New York: Routledge.

Meganathan, R. (2011). Language policy in education and the role of English in India: From library language to language of empowerment. In H. Coleman (Ed.), Dreams and realities: developing countries and the English language (pp. 57-85). London: British Council.

Miles, S. W. (2014). Spaced vs. massed distribution instruction for L2 grammar learning. System, 42, 412428. https://doi.org/10.1016/j.system.2014.01.014

Nakata, T. (2015). Effects of expanding and equal spacing on second language vocabulary learning: Does gradually increasing spacing increase vocabulary learning? Studies in Second Language Acquisition, 37, 677-711.https://doi.org/10.1017/S0272263114000825

Pan, S. C., Tajrana, J., Loveletta, J., Osuna, J., \& Rickard, T. (2018). Does interleaved practice enhance foreign language learning? The effects of training schedule on Spanish verb conjugation skills. Journal of Educational Psychology, 111(7). https://doi.org/10.1037/edu0000336

Pavlik, P.I., \&Anderson,J.R.(2008).Using a model to compute the optimal schedule of practice. Journal of Experimental Psychology Applied, 14 (2), 101-117.https://doi.org/10.1037/1076- 898X.14.2.101

Porter, J. M., Landin, D., Hebert, E. P., \& Baum, B. (2007). The effects of three levels of contextual interference on performance outcomes and movement patterns in golf skills. International journal of Sports Science \& Coaching, 2(3), 243-255.https://doi.org/10.1260/174795407782233100

Porter, J. M., \& Magill, R. A. (2010). Systematically increasing contextual interference is beneficial for learning sport skills. Journal of Sports Sciences, 28, 12771285.https://doi.org/10.1080/02640414.2010.502946

Rogers, J. (2017). The spacing effect and its relevance to second language acquisition. Applied Linguistics, 38, 906-911.https://doi.org/10.1093/applin/amw052

Rohrer, D., \& Taylor, K. M. (2007). The shuffling of mathematics problems improves learning. Instructional Science, 35, 481-498. https://doi.org/10.1007/S11251-007-9015-8

Sailaja, P. (2009). Indian English. Edinburgh: Edinburgh University Press.

Schneider, V. I., Healy, A. F., \& Bourne, L. E. (1998). Contextual interference effects in foreign language vocabulary acquisition and retention. In A. F. Healy \& L. E. Bourne (Eds.), Foreign language learning: Psycholinguistic studies on training and retention (pp. 77-90). Mahwah, NJ: Erlbaum.

Schneider, V. I., Healy, A. F., \& Bourne, L. E. (2002). What is learned under difficult conditions is hard to forget: Contextual interference effects in foreign vocabulary acquisition, retention, and transfer. Journal of Memory and Language, 46, 419-440. https://doi.org/10.1006/jmla.2001.2813 
Soderstrom, N. C., \& Bjork, R. A. (2015). Learning versus performance: An integrative review. Perspectives on Psychological Science,10(2), 176-199.https://doi.org/10.1177/1745691615569000

Wahlheim, C. N., Dunlosky, J., \& Jacoby, L. L. (2011). Spacing enhances the learning of natural concepts: An investigation of mechanisms, metacognition, and aging. Memory \& Cognition, 39, 750-763. https://doi.org/10.3758/s13421-010-0063-y

Wong, A. W.-K., Whitehill, T. L., Ma, E. P.-M., \& Masters, R. (2013). Effects of practice schedules on speech motor learning. International Journal of Speech-Language Pathology, 15, 511523.https://doi.org/:10.3109/17549507.2012.761282

Yadav, S.K. (2011). National study on ten-year school curriculum implementation. New Delhi: NCERT.

Zulkiply, N., \& Burt, J. S. (2013). The exemplar interleaving effect in inductive learning: Moderation by the difficulty of category discriminations. Memory \& Cognition, 41(1), 1627.https://doi.org/10.3758/s13421-012-0238-9

\section{Appendix 1}

Profile of the learner participants (BP: Block practice; IL: Interleaving; TU: Tezpur University)

\begin{tabular}{cccccccc}
\hline $\begin{array}{c}\text { Sl. } \\
\text { No. }\end{array}$ & $\begin{array}{c}\text { *Pseudonyms } \\
\text { of the } \\
\text { participants }\end{array}$ & Group & Sex & Age & Level of Education & $\begin{array}{c}\text { Academic } \\
\text { Discipline }\end{array}$ & Institution \\
\hline 1 & MBI09 & BP & Female & 19 & Undergraduate & Science & TU \\
2 & CHB09 & BP & Female & 18 & Undergraduate & Science & TU \\
3 & MSB07 & IL & Female & 19 & Undergraduate & Science & TU \\
4 & MSB05 & BP & Female & 19 & Undergraduate & Science & TU \\
5 & CHI06 & IL & Female & 18 & Undergraduate & Science & TU \\
6 & MSB06 & IL & Female & 19 & Undergraduate & Science & TU \\
7 & MSB08 & BP & Female & 18 & Undergraduate & Science & TU \\
8 & MSB09 & IL & Female & 19 & Undergraduate & Science & TU \\
9 & MSI20 & IL & Female & 19 & Undergraduate & Science & TU \\
10 & MSI14 & IL & Female & 19 & Undergraduate & Science & TU \\
11 & MBI21 & IL & Female & 19 & Undergraduate & Science & TU
\end{tabular}


20 | Rupkatha Journal, Vol. 13, No. 4, 2021

\begin{tabular}{|c|c|c|c|c|c|c|c|}
\hline 12 & $\mathrm{CHI} 14$ & $\mathrm{BP}$ & Female & 18 & Undergraduate & Science & TU \\
\hline 13 & $\mathrm{CHI} 16$ & $\mathrm{BP}$ & Female & 19 & Undergraduate & Science & TU \\
\hline 14 & PHI19 & $\mathrm{IL}$ & Female & 18 & Undergraduate & Science & TU \\
\hline 15 & MBI02 & $\mathrm{BP}$ & Female & 18 & Undergraduate & Science & TU \\
\hline 16 & MBI30 & $\mathrm{BP}$ & Female & 19 & Undergraduate & Science & TU \\
\hline 17 & $\mathrm{CHI} 20$ & $\mathrm{IL}$ & Female & 19 & Undergraduate & Science & TU \\
\hline 18 & PHI17 & IL & Male & 19 & Undergraduate & Science & TU \\
\hline 19 & PHI20 & $\mathrm{IL}$ & Male & 19 & Undergraduate & Science & TU \\
\hline 20 & PHI05 & $\mathrm{BP}$ & Male & 18 & Undergraduate & Science & TU \\
\hline 21 & MSI02 & $\mathrm{IL}$ & Male & 18 & Undergraduate & Science & TU \\
\hline 22 & $\mathrm{CHI01}$ & $\mathrm{BP}$ & Male & 19 & Undergraduate & Science & TU \\
\hline 23 & $\mathrm{CHI} 21$ & $\mathrm{IL}$ & Male & 19 & Undergraduate & Science & TU \\
\hline 24 & MSB12 & $\mathrm{IL}$ & Male & 19 & Undergraduate & Science & TU \\
\hline 25 & $\mathrm{CHI} 24$ & IL & Male & 18 & Undergraduate & Science & TU \\
\hline 26 & MSI13 & $\mathrm{IL}$ & Male & 19 & Undergraduate & Science & TU \\
\hline 27 & PHI25 & $\mathrm{BP}$ & Male & 18 & Undergraduate & Science & TU \\
\hline 28 & MSI22 & IL & Male & 18 & Undergraduate & Science & TU \\
\hline 29 & MSB11 & $\mathrm{IL}$ & Male & 19 & Undergraduate & Science & TU \\
\hline 30 & $\mathrm{CHI} 22$ & $\mathrm{BP}$ & Male & 18 & Undergraduate & Science & TU \\
\hline 31 & PHI16 & $\mathrm{BP}$ & Male & 19 & Undergraduate & Science & TU \\
\hline 32 & MSI18 & $\mathrm{IL}$ & Male & 18 & Undergraduate & Science & TU \\
\hline 33 & CHB11 & $\mathrm{BP}$ & Male & 19 & Undergraduate & Science & TU \\
\hline 34 & $\mathrm{CHI} 26$ & $\mathrm{BP}$ & Male & 18 & Undergraduate & Science & TU \\
\hline 35 & PHI23 & IL & Male & 19 & Undergraduate & Science & TU \\
\hline
\end{tabular}


English Speaking Skill and Indian Undergraduate ESL Learners: Interleaving or Block Practice?

* Based on the official programme code and enrolment number of the learner participants.

\section{Appendix 2}

\section{Sample of the questionnaire}

Please rate the following statements (1-5) in the following way.

\section{Strongly Disagree} 1
2

\section{Strongly Agree}

4 5

1. What I learnt in the session was not significant for my career goals.

2. The teacher's behaviour in the session was pleasant.

3. The session was extremely useful in learning things needed for my career goals.

4. The teacher behaved very rudely in the session.

5. I got to learn many new things in the session.

6. I could easily understand and follow the instructions of the teacher in the session.

7. No new things were taught in the session.

8. The lesson taught in the session was beyond my comprehension.

9. I will be able to improve my self-image by what I have learnt in the session.

10. The lesson I learnt in the session is not going to contribute to my social image.

11. I practiced many important language skills in the session which will help me in my career.

12. The teacher was very affectionate during the session.

13. The teacher did not care for my understanding of the lesson.

14. I could learn lots of new language skills in the session.

15. I am sure that the language skills I learnt in the session are not going to help me improve my self image.

16. I did not like the teacher's attitude towards me in the session as it was not at all pleasant.

17. I thought that I needed the language skills taught in the session to realize my career goals. 
18. The teacher taught the lessons in the session so lucidly that I could understand them very easily.

19. The session could offer no new language skills for me to learn.

20. The language skills that I learnt in the session could not contribute to the enhancement of my social-image.

Sujata Kakoti is a PhD scholar in the Department of English, Tezpur University. She is working on the effect of different language teaching methods on L2 speaking proficiency.

Dr Sarat Kumar Doley works as an Assistant Professor in the Department of English, Tezpur University. His research interest is in English Language Education. 